\title{
Biomechanical analysis of stair ascent in persons with Chopart amputation
}

Prosthetics and Orthotics International 2020, Vol. 44(3) |64-17|

(C) The International Society for Prosthetics and Orthotics 2020 Article reuse guidelines: sagepub.com/journals-permissions DOI: 10.1 | 177/0309364619900737 journals.sagepub.com/home/poi

(S)AGE

\author{
T Kaib', J Schäfer',2, J Block', DWW Heitzmann' ${ }^{(\mathbb{D},}$ \\ C Putz', M Alimusaj' and SI Wolf' 1
}

\begin{abstract}
Background: Compared to walking on level ground, ascending stairs requires a large range of motion not only of the hip and knee joint, but also of the ankle joint. The prosthesis often worn by persons with partial foot amputation largely prevents the ankle motion needed during stair ascent.

Objectives: Aim of this study was to assess subjects with a Chopart amputation utilizing a clamshell device during stair ascent to identify potential biomechanical deficits.

Study design: Cross-sectional study with reference group.

Methods: Six subjects with unilateral Chopart amputation and 17 unimpaired subjects underwent three-dimensional motion analysis while ascending stairs in a step-over-step manner.

Results: During weight acceptance, the involved side showed increased external hip-flexing and reduced knee-flexing moments and the sound side a higher ankle power than in the control group. The sound side showed higher external knee-flexing, dorsi-flexing, and hip-adducting moments than the controls during weight acceptance.

Conclusion: The mechanism observed on the involved side differs from that in controls, but is comparable to the mechanisms used by subjects with transtibial amputation reported in the literature. However, compensatory movements on the sound side take place at the ankle and knee joint, differing from subjects with more proximal amputations.
\end{abstract}

\section{Clinical relevance}

This study underpins the importance of adequate foot leverage and ankle function in cases of partial foot amputation, particularly in transfer situations such as stair ascent. If ankle range of motion is adequate, prosthetic/orthotic devices combining shank leverage with a hinged spring mechanism at the ankle may be promising.

\section{Keywords}

Chopart amputation, prosthesis, biomechanics, gait, stairs

\section{Background}

In Germany, partial foot amputations are typically caused by vascular disorders, often secondary to diabetes, trauma, or tumors. ${ }^{1}$ The exarticulation of the foot's Chopart joint represents the first possible amputation level of the hindfoot, where only the calcaneus and talus remain. ${ }^{2}$ The Chopart amputation (CA), promising functional advantages over more proximal amputations, salvages the ankle joint and the sole skin, which is capable of full-body weight-bearing; does not cause a leg-length discrepancy; and enables the subjects to walk "barefoot" so that proprioceptive feedback can be acquired. ${ }^{3}$ Unfortunately, subjects with $\mathrm{CA}$ are prone to developing a severe hindfoot equinus over time due to muscular imbalance of the tibia-gastroc-soleus complex caused either by a developing weakness of dorsiflexors or by dorsiflexors that were not restored during surgery. ${ }^{4}$ In addition, the decrease in foot length results in a loss of the biomechanical fore foot lever, leading to a complete loss of the ability to push off in late stance. ${ }^{5}$ In order to improve standing and walking in these individuals, a prosthetic device is

'Clinic for Orthopedics and Trauma Surgery, Heidelberg University Hospital, Heidelberg, Germany

${ }^{2}$ University of Applied Science Koblenz, Remagen, Germany

\section{Corresponding author:}

SI Wolf, Clinic for Orthopedics and Trauma Surgery, Heidelberg University Hospital, Schlierbacher Landstr. 200a, 69II8 Heidelberg, Germany.

Email: Sebastian.Wolf@med.uni-heidelberg.de

Associate Editor: Reza Safari 


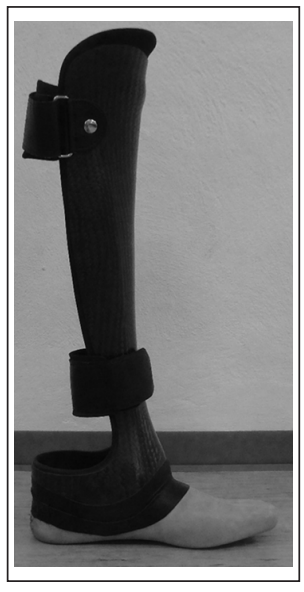

Figure I. The clamshell device used in this study.

mandatory to restore the lost biomechanical leverage. ${ }^{6}$ Currently, both low-profile and high-profile devices are routinely prescribed. High-profile prostheses, in particular the clamshell prosthesis (CSP) (Figure 1), hold promise of being a better option for re-acquiring the lost foot lever for walking on level ground..$^{7-9}$ The CSP combines a rather rigid construction with a ventral shell. It limits the ankle range of motion (ROM) but enables the user to shift the center of pressure onto the forefoot while supporting the high external dorsi-flexing moment induced by their body weight. In contrast, the low-profile Chopart prosthesis does not restrict the ankle ROM in this way but may not offer sufficient foot leverage. ${ }^{7}$ Effective foot leverage may to some extent be a tradeoff for limited ankle ROM.

Everyday life comprises more than just walking on level ground; other activities require greater hip, knee, and ankle joint ROM, moments, and power generation/absorption compared to level ground gait. ${ }^{10-12}$ This includes ascending and descending stairs or ramps. The general gait pattern when ascending stairs in unimpaired subjects is the step-over-step strategy, where both limbs contribute to lifting the center of mass $(\mathrm{CoM})$ to the next stair. ${ }^{13} \mathrm{Up}$ until now and to the best of our knowledge, no study has investigated stair walking in subjects with partial foot amputation. However, it is known that subjects with transtibial amputation (TTA) typically are able to make use of the step-over-step strategy when ascending stairs. In doing so, they induce a greater hip moment to elevate the body during stance phase on their involved side, compared to unimpaired persons who predominantly rely on their knee moment. ${ }^{14,15}$ Subjects with CA who are provided with clamshell devices face a functional situation which is comparable to subjects with TTA using carbon fiber prostheses, since in both cases the ankle ROM is limited to the degree to which the respective carbon fiber foot plate can be deformed. Also in patients who suffered severe lower leg injuries (SLI) and who are provided with specific ankle foot orthoses (AFOs), as described by Aldridge Whitehead et al. ${ }^{16}$ the ankle ROM is relevantly restricted and may therefore limit performance in ascending stairs. The aim of this study was, therefore, to assess stair ascent in subjects with CA when using clamshell prostheses. In particular, we wanted to assess potential biomechanical deficits in comparison to the typical gait of subjects without impairment and to set these deficits in the context of the traumatic conditions of TTA and of SLI, which induce a similar lever arm dysfunction at the foot and ankle.

\section{Methods}

Subjects with unilateral CA and K-Level $3-4^{17}$ were recruited for this study to undergo instrumented threedimensional (3D) gait analysis and a short clinical examination. To participate, they had to have a well-fitting CSP (Figure 1), as confirmed by a certified prosthetist. Exclusion criteria were residual limb issues and the need for additional walking aids (e.g. crutches, canes, etc.). Healthy able-bodied subjects were recruited to undergo the same protocol in order to obtain reference data for typical stair case ascent. All subjects included in this study provided written informed consent to participate in this study, which was approved by the local ethics commission (S-625/2016).

The prosthesis under investigation was of carbon fiber construction holding the residual limb volume in a distal socket. Furthermore, it transfers load to the shank via a ventral shell support, similar to a ground reaction $\mathrm{AFO}$, but without a dedicated ankle joint as in hinged $\mathrm{AFOs}^{18-20} \mathrm{~A}$ carbon fiber foot plate (i.e. Chopart plate, Össur, Reykjavik, Iceland) beneath the socket provides foot motion through deformation. Quality standards of our department for prosthetics and orthotics, in which prostheses were manufactured, include prosthetic bench (static) alignment which was performed according to the manufacturer's guidelines. Dynamic prosthetic alignment was conducted following alignment recommendations of Blumentritt et al. ${ }^{21}$ in the sagittal plane for below-knee prostheses, as there are no general alignment recommendations for the CSP. ${ }^{21}$ Therefore, the vertical load line measured with an L.A.S.A.R. posture device (Otto Bock Duderstadt, Germany) on the prosthetic side was confirmed to lie $0-15 \mathrm{~mm}$ anteriorly of the knee joint center as defined by Nieter ${ }^{22}$ in the sagittal plane, and run at the lateral patella edge in the coronal plane while standing still..$^{22}$ The anterior-posterior position of the carbon fiber foot plate was predefined by the anatomical ankle joint. ${ }^{20}$

In the clinical examination, residual foot length was measured when sitting as the distance from the heel to the foremost prominence of the residual foot and reported as a relative measure of the distance from heel to toe of the uninvolved foot. Furthermore, strength and ROM of the remaining joints were determined and documented ${ }^{23}$ if they deviated from normal as this may have secondary influence on the gait data to be collected. Instrumented 3D 


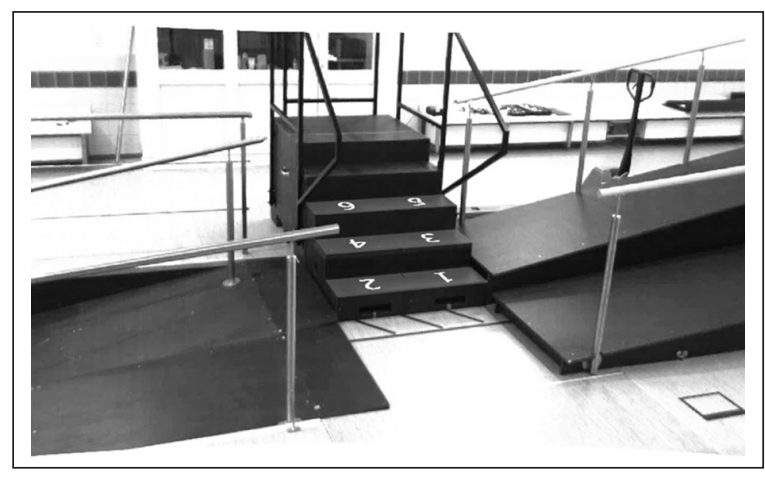

Figure 2. The instrumented five-step staircase (height: $16 \mathrm{~cm}$; depth: $27 \mathrm{~cm}$; width: $100 \mathrm{~cm}$ ) with handrails on each side. The left side $(2,4,6)$ and the right side $(I, 3,5)$ are placed on one force plate each.

gait analysis was performed with all participants on a fivestep staircase (Figure 2). The dominant side of the controls was determined using three functional tests: ball kick, step-up, and balance recovery, introduced by Hoffman et al. ${ }^{24}$ For the subjects with amputation, the affected limb was classified as the non-dominant side. All participants were asked to utilize the step-over-step strategy starting with the dominant side on the first step. Reflective markers were placed in accordance with conventional clinical gait analysis procedures using the Plug-in-Gait Model (Vicon, Oxford, United Kingdom). ${ }^{25,26}$ Four additional markers were placed on the shoulder girdle (spinous process of the seventh cervical vertebra, left and right acromion, and jugular notch) and were used to observe trunk motion in relation to the global reference frame. ${ }^{27} \mathrm{~A}$ Vicon 3D motion analysis system (Vicon, Oxford, United Kingdom), including twelve T40 cameras running at $120 \mathrm{~Hz}$ and two force plates (AMTI, Inc., Watertown, MA, United States), read out at $1080 \mathrm{~Hz}$, was used.

For the stair case, the first three steps were divided into two separate boxes that were not mechanically coupled, whereby the left and right stair step box can each be bolted to a separate physical force plate. Each physical force plate was subdivided into three individual smaller virtual force plates, located on top of each individual step (Figure 2). As the subjects do not physically step onto the force plates but rather onto the stairs mounted on top of them, force plate data are recalculated in a post-processing step to obtain the ground reaction forces (GRFs) acting on the surface of the stairs by applying an algorithm described previously. ${ }^{28}$ For each subject, at least five valid force plate hits were collected for each limb and joint kinematics and kinetics were averaged across trials for subsequent data processing.

For visual inspection, group averages of the involved and sound sides as well as of the controls were calculated (Figure 3). Sub-phases of the stance phase according to the phase definition of Novak $^{29}$ for stair ambulation were analyzed, namely, weight acceptance (WA; first double support), followed by pull-up (single support), and forward continuance (FCo; second double support). ${ }^{29}$ Time-distance parameters, vertical GRFs, and sagittal and frontal kinematics and kinetics of the trunk, hip, knee, and ankle joint were analyzed. Joint kinetics were scaled to body weight, that is, moments in $\mathrm{Nm} / \mathrm{kg}$ and powers in $\mathrm{W} / \mathrm{kg}$, respectively. For the control group, data from the dominant and non-dominant sides were averaged.

Due to explorative character of this study with a small sample size, we report descriptive statistics on the basis of group averages and standard deviation.

\section{Results}

Within the recruitment period of 1 year, we were able to include nine subjects with unilateral CA for the study. However, for one subject the force plate arrangement on the stair case was not yet available and in two other cases we could not obtain adequate kinetics because a handrail was used. Therefore, in total, data were obtained for six subjects with unilateral CA of mobility level (K-level) 3-4. ${ }^{17}$ Subject characteristics are presented in Table 1, none having any deficits in strength or passive ROM in the hip or knee. Seventeen able-bodied subjects (eight male; nine female; age: $28 \pm 6$ years; height: $1.76 \pm 0.07 \mathrm{~m}$; weight: $71 \pm 10 \mathrm{~kg}$ ) were recruited and assessed for reference.

\section{Temporospatial parameters and GRFs}

The subjects with amputation ascended the stairs slower $(0.40 \pm 0.03 \mathrm{~m} / \mathrm{s})$ than the controls $(0.45 \pm 0.03 \mathrm{~m} / \mathrm{s})$, due to reduced cadence $(88.8 \pm 8.0 \mathrm{steps} / \mathrm{min}$ vs $96.1 \pm 5.8 \mathrm{steps} /$ min; Table 2). Furthermore, the stance phase was reduced on the involved side with $59.6 \% \pm 1.4 \%$ gait cycle $(\mathrm{GC})$ compared to the controls $(62.6 \% \pm 1.5 \% \mathrm{GC})$. The maximum vertical GRF on the involved side was also lower both around opposite foot off(i.e. end of WA $)(9.7 \pm 0.4 \mathrm{Nm} /$ $\mathrm{kg})$ and in FCo $(10.8 \pm 0.6 \mathrm{Nm} / \mathrm{kg})$ than in the controls $(11.1 \pm 0.7$ and $11.8 \pm 0.7 \mathrm{Nm} / \mathrm{kg}$, respectively), whereas the minimum vertical GRF in pull-up was higher $(7.9 \pm 0.5 \mathrm{Nm} / \mathrm{kg}$ vs $7.1 \pm 0.7 \mathrm{Nm} / \mathrm{kg})$. Inversely, on the sound side the GRF was larger around opposite foot off $(13.0 \pm 0.7 \mathrm{~N} \mathrm{~m} / \mathrm{kg})$ than in the controls $(11.1 \pm 0.7 \mathrm{~N} \mathrm{~m} / \mathrm{kg})$ and on the involved side $(9.7 \pm 0.4 \mathrm{Nm} / \mathrm{kg})$, whereas the minimum GRF at pull-up $(7.9 \pm 0.5 \mathrm{Nm} / \mathrm{kg})$ was higher than in the controls $(7.1 \pm 0.7 \mathrm{Nm} / \mathrm{kg})$.

\section{Kinematics}

Regarding trunk kinematics, the only finding in addition to increased forward tilt at foot strike (FS; in the literature also referred to as initial contact) of the involved side was that the subjects with amputation held their trunk slightly more toward the involved leg in stance phase compared to controls (see trunk obliquity in Table $3,2.9^{\circ}$ vs $1.1^{\circ}$ and also 


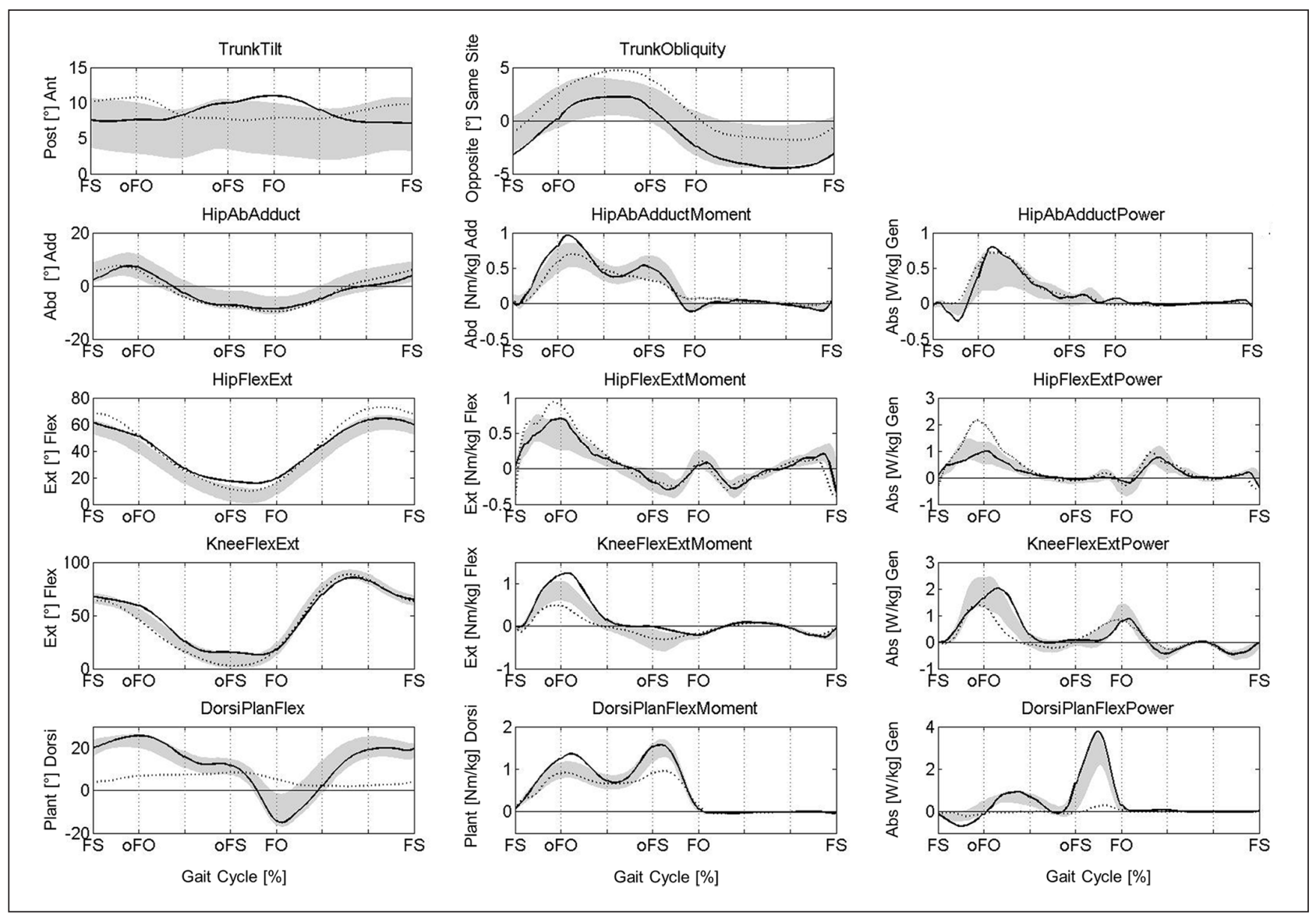

Figure 3. Kinematics and kinetics of the trunk, hip, knee, and ankle in the frontal and sagittal plane. Dashed line $=$ involved, solid line $=$ sound side, gray band $=$ controls (mean and standard deviation) .

Table I. Anthropometric data of the subjects with CA specifically including relative foot (stump) length and passive ankle ROM as tested in the clinical examination.

\begin{tabular}{lllllllll}
\hline ID & Gender & $\begin{array}{l}\text { Age } \\
\text { (years) }\end{array}$ & $\begin{array}{l}\text { Height } \\
(\mathbf{m})\end{array}$ & $\begin{array}{l}\text { Weight } \\
(\mathbf{k g})\end{array}$ & $\begin{array}{l}\text { Time since } \\
\text { amputation (years) }\end{array}$ & $\begin{array}{l}\text { Reason for } \\
\text { amputation }\end{array}$ & $\begin{array}{l}\text { Residual foot } \\
\text { length }(\%)\end{array}$ & $\begin{array}{l}\text { Involved side's } \\
\text { ankle ROM }\left({ }^{\circ}\right)\end{array}$ \\
\hline 53919 & Female & 54 & 1.68 & 62 & 5 & Trauma & 48 & 30 \\
54346 & Male & 49 & 1.79 & 92 & 6 & Trauma & 49 & 20 \\
54347 & Male & 51 & 1.82 & 80 & 4 & Trauma & 36 & 0 \\
54915 & Male & 35 & 1.84 & 95 & 18 & Trauma & 46 & 15 \\
54923 & Male & 56 & 1.79 & 91 & 35 & Trauma & 44 & 40 \\
54967 & Male & 60 & 1.82 & 92 & 23 & Tumor & 42 & 20 \\
Average & & 50.8 & 1.80 & 85.3 & 15.2 & & 44.2 & 20.8 \\
\hline
\end{tabular}

CA: Chopart amputation; ROM: range of motion.

Figure 3). Furthermore, the subjects with amputation flexed their hip more at FS and in swing than did the controls $\left(68.8^{\circ}\right.$ vs $58.2^{\circ}$, and $73.3^{\circ}$ vs $61.1^{\circ}$, respectively), whereas the minimum hip flexion in stance was larger when comparing the sound side with controls $\left(14.9^{\circ}\right.$ vs $\left.5.7^{\circ}\right)$. The only finding at the knee was that the involved side was slightly less flexed at FS compared to the sound side. The CSP showed largely reduced values for dorsiflexion at FS and in stance, whereas maximum plantarflexion was reduced compared both to the sound side and to controls. No differences were found in these parameters when comparing the sound side ankles to controls.

\section{Kinetics}

In the sagittal plane, external hip-flexing moments during WA on the involved side were greater than in the controls $(1.03 \pm 0.23 \mathrm{Nm} / \mathrm{kg}$ vs $0.67 \pm 0.20 \mathrm{Nm} / \mathrm{kg}$, Table 4). 
Table 2. Mean and standard deviation for time distance parameters and vertical ground reaction forces (in N/kg) for involved and sound side and for controls.

\begin{tabular}{llrr}
\hline Parameter & Involved side & Sound side & Controls \\
\hline Speed $(\mathrm{m} / \mathrm{s})$ & $0.40 \pm 0.03$ & $0.40 \pm 0.03$ & $0.45 \pm 0.03$ \\
Cadence (steps/min) & $88.8 \pm 8.0$ & $88.8 \pm 8.0$ & $96.1 \pm 5.8$ \\
Stance phase duration (\% GC) & $59.6 \pm 1.4$ & $63.3 \pm 2.4$ & $62.6 \pm 1.5$ \\
Maximum vertical GRF around oFo & $9.7 \pm 0.4$ & $13.0 \pm 0.7$ & $11.1 \pm 0.7$ \\
Minimum GRF vertical GRF in pull-up & $7.9 \pm 0.5$ & $6.8 \pm 0.7$ & $7.1 \pm 0.7$ \\
Maximum vertical GRF in FCo & $10.8 \pm 0.6$ & $12.6 \pm 1.2$ & $11.8 \pm 0.7$ \\
\hline
\end{tabular}

GC: gait cycle; GRF: ground reaction force; oFo: opposite foot off; FCo: forward continuance.

Table 3. Mean and standard deviation of joint kinematics of trunk, hip, knee, and ankle (in degrees) for involved and sound side and for controls.

\begin{tabular}{lrrr}
\hline Parameter & Involved side & Sound side & Controls \\
\hline Trunk tilt at FS & $10.2 \pm 3.0$ & $7.6 \pm 2.7$ & $7.2 \pm 3.5$ \\
Trunk obliquity at FS & $-1.2 \pm 1.7$ & $-3.2 \pm 2.3$ & $-1.3 \pm 1.6$ \\
Mean trunk tilt in stance & $8.9 \pm 3.1$ & $8.8 \pm 2.7$ & $6.4 \pm 3.4$ \\
Mean trunk obliquity in stance & $2.9 \pm 0.5$ & $0.7 \pm 2.1$ & $1.1 \pm 1.5$ \\
Hip flexion at FS & $68.8 \pm 5.4$ & $61.4 \pm 5.4$ & $58.2 \pm 5.3$ \\
Minimum hip flexion in stance & $9.6 \pm 7.4$ & $14.9 \pm 5.2$ & $5.7 \pm 5.3$ \\
Maximum hip flexion in swing & $73.3 \pm 6.4$ & $64.7 \pm 6.3$ & $61.6 \pm 5.2$ \\
Hip abduction at FS & $5.1 \pm 4.9$ & $2.3 \pm 5.6$ & $5.1 \pm 3.7$ \\
ROM hip abduction & $17.6 \pm 2.6$ & $17.4 \pm 7.1$ & $16.1 \pm 4.7$ \\
Knee flexion at FS & $64.2 \pm 6.3$ & $67.7 \pm 4.4$ & $66.4 \pm 4.6$ \\
Minimum knee flexion in stance & $2.4 \pm 8.3$ & $11.9 \pm 5.8$ & $6.5 \pm 6.6$ \\
Maximum knee flexion in swing & $88.6 \pm 5.8$ & $86.0 \pm 6.5$ & $88.6 \pm 4.3$ \\
Dorsiflexion at FS & $3.6 \pm 4.1$ & $20.0 \pm 3.3$ & $19.8 \pm 3.9$ \\
Maximum dorsiflexion in stance & $8.6 \pm 4.2$ & $25.8 \pm 4.4$ & $23.7 \pm 2.9$ \\
Minimum dorsiflexion in stance & $3.6 \pm 4.2$ & $-15.1 \pm 7.9$ & $-9.3 \pm 7.5$ \\
\hline
\end{tabular}

FS: foot strike; ROM: range of motion.

Conversely, external knee-flexing moment and power generation during pull-up were lower on the involved side than in controls $(0.51 \pm 0.15 \mathrm{Nm} / \mathrm{kg}$ and $1.56 \pm 0.43 \mathrm{~W} / \mathrm{kg}$ vs $0.85 \pm 0.21 \mathrm{Nm} / \mathrm{kg}$ and $2.12 \pm 0.52 \mathrm{~W} / \mathrm{kg}$, respectively), with the external knee-flexing moments also being smaller than on the sound side - which were in fact much larger $(1.27 \pm 0.16 \mathrm{Nm} / \mathrm{kg})$. In the frontal plane, external hipadducting moments on the sound side $(0.99 \pm 0.22 \mathrm{Nm} /$ $\mathrm{kg}$ ) were greater than those on the involved side $(0.72 \pm 0.10 \mathrm{Nm} / \mathrm{kg})$ and on controls $(0.72 \pm 0.17 \mathrm{~N} \mathrm{~m} / \mathrm{kg})$ during pull-up. Furthermore, ankles on the involved side showed reduced dorsi-flexing moments $(0.94 \pm 0.08 \mathrm{~N} \mathrm{~m} /$ $\mathrm{kg})$ and almost no power generation $(0.05 \pm 0.04 \mathrm{~W} / \mathrm{kg})$ compared to the sound side $(1.37 \pm 0.15 \mathrm{Nm} / \mathrm{kg}, 1.03 \mathrm{~W} /$ $\mathrm{kg}$, respectively).

\section{Discussion}

The aim of this study was to assess potential biomechanical deficits in subjects with CA when ascending stairs using clamshell prostheses. Walking speed and cadence being about $10 \%$ smaller in the group with amputation than in controls suggests a challenge in ascending stairs. The reduced walking speed of this group may have had a secondary effect on the joint powers reported here, but these effects may not fully explain the differences we found.

In healthy able-bodied subjects, the ankle ROM on stairs is about $40^{\circ}$ (Figure 3, bottom left). In subjects with $\mathrm{CA}$, the passive ROM is often reduced due to develop contractures and in fact ranged from $40^{\circ}$ down to $0^{\circ}$ (i.e. fixed) in our cohort (Table 1). However, when using a CSP, the foot/ankle motion is limited to the deformation of the foot plate. This situation is similar to subjects with TTA when using prosthetic feet and to subjects with SLI when using an AFO, in which the foot/ankle motion is also limited to a few degrees. ${ }^{15,16,30}$ To a certain extent, this is the tradeoff for offering adequate and loadable foot leverage, which was reduced by more than $50 \%$ on average in our study patients (compare relative foot length in Table 1). In all three clinical conditions, the missing ankle dorsiflexion leads to a larger hip flexion of the involved limb to place 
Table 4. Mean and standard deviation of joint kinetics of hip, knee, and ankle for involved and sound side as well as controls (moments in $\mathrm{Nm} / \mathrm{kg}$ and powers in $\mathrm{W} / \mathrm{kg}$ ).

\begin{tabular}{lrrr}
\hline Parameter & Involved side & Sound side & Controls \\
\hline Maximum hip-extending moments in FCo & $0.51 \pm 0.14$ & $0.50 \pm 0.15$ & $0.43 \pm 0.1 \mathrm{I}$ \\
Maximum hip-flexing moments in WA & $1.03 \pm 0.23$ & $0.75 \pm 0.28$ & $0.67 \pm 0.20$ \\
Maximum hip-abducting moments in FCo & $0.08 \pm 0.05$ & $0.15 \pm 0.05$ & $0.10 \pm 0.04$ \\
Maximum hip-adducting moments in pull-up & $0.72 \pm 0.10$ & $0.99 \pm 0.22$ & $0.72 \pm 0.17$ \\
Maximum hip extension power absorption in FCo & $-0.65 \pm 0.49$ & $-0.41 \pm 0.30$ & $-0.57 \pm 0.27$ \\
Maximum hip extension power generation in WA & $2.28 \pm 0.56$ & $1.17 \pm 0.4 \mathrm{I}$ & $1.33 \pm 0.40$ \\
Maximum hip abduction power absorption in WA & $-0.09 \pm 0.06$ & $-0.28 \pm 0.17$ & $-0.12 \pm 0.06$ \\
Maximum hip abduction power generation in pull-up & $0.82 \pm 0.16$ & $0.93 \pm 0.51$ & $0.59 \pm 0.27$ \\
Maximum knee-extending moments in FCo & $-0.43 \pm 0.23$ & $-0.31 \pm 0.08$ & $-0.43 \pm 0.17$ \\
Maximum knee-flexing moments in pull-up & $0.51 \pm 0.15$ & $1.27 \pm 0.16$ & $0.85 \pm 0.21$ \\
Maximum knee extension power absorption in FCo & $-0.65 \pm 0.31$ & $-0.60 \pm 0.30$ & $-0.62 \pm 0.19$ \\
Maximum knee extension power generation in pull-up & $1.56 \pm 0.43$ & $2.13 \pm 0.41$ & $2.12 \pm 0.52$ \\
Maximum dorsi-flexing moments around oFo & $0.94 \pm 0.08$ & $1.37 \pm 0.15$ & $1.01 \pm 0.18$ \\
Maximum dorsi-flexing moments in pull-up & $0.99 \pm 0.13$ & $1.67 \pm 0.19$ & $1.5 \mathrm{I} \pm 0.20$ \\
Maximum dorsiflexion power generation around oFo & $0.05 \pm 0.04$ & $1.03 \pm 0.48$ & $0.79 \pm 0.25$ \\
Maximum dorsiflexion power generation in pull-up & $0.32 \pm 0.16$ & $4.06 \pm 0.78$ & $3.01 \pm 0.69$
\end{tabular}

FCo: forward continuance; WA: weight acceptance; oFo: opposite foot off.

the involved foot adequately on the stair. Subjects with CA used their prosthetic forefoot during WA, placing their prosthesis onto the step solely with the forefoot. To compensate for reduced prosthetic ankle dorsiflexion during WA, the rather rigid clamshell construction enabled the user to transfer force via the CSPs ventral shell, producing a rigid forefoot lever. ${ }^{8,9}$ This foot positioning and rigid forefoot lever increased the external hip-flexing moment, increased hip power generation, and reduced the kneeflexing moment to elevate the body of the involved side, which is comparable to the situation with TTA or SLI. ${ }^{15,16,30}$ However, decreased knee moments during WA are lower than in the controls (but similar to those in patients with SLI) and still much greater than the knee moments in subjects with TTA reported in other studies. ${ }^{15,30,31}$ At the same instant the sound side was in FCo with the foot still placed on the stair below, no pronounced plantarflexion was observed but ankle power generation was more pronounced than in controls to lift the body upward comparably to subjects with TTA and SLI, respectively. ${ }^{15,16}$ The missing active plantarflexion of the prosthetic device when preparing step contact for the sound limb potentially leads to a lowered vertical CoM position, which may be detrimental when the CoM needs to be lifted to the next step. ${ }^{14,30}$

Furthermore, subjects with CA reduced their external hip-adducting moments by shifting their upper body toward the involved side around the end of FCo. This finding - known as "compensated Trendelenburg"-is associated with hip abductor weakness and can also be found in subjects with TTA; ${ }^{32,33}$ however, no reports have been published yet in which trunk motion was monitored in cases of SLI. Participants in the present study all showed full strength in their hip abductors as assessed in the clinical examination. Subjects with partial foot amputation examined in previous work did not demonstrate a hip abductor weakness either. ${ }^{34}$ Consequently, this mechanism seems to have a different origin. Potentially, this trunk movement is compensatory to stabilize the hip in the frontal plane due to a missing prosthetic subtalar joint which would facilitate foot inversion and eversion. The missing adaption in the ankle joint to stabilize in the frontal plane shifts the adapting motion that is needed into the upper body to reduce the moments applied in all joints of the involved side.

After placing the sound limb on the next step, the sound side needs to compensate for the insufficient push off on the involved side to achieve the propulsion that is necessary. The main compensatory mechanisms on the sound side occur in the ankle and knee joint during WA. They induce a greater external dorsal- and knee-flexing moment during WA and pull-up on the sound side, resulting in greater ankle power generation; simultaneously, the vertical GRF increases on the sound side. The increased external knee-flexing moments are comparable to those in subjects with TTA; however, subjects with TTA seem to decrease their external hip-flexing moments and create an external dorsal-flexing moment as in controls - a behavior which seems to differ from that in subjects with CA. ${ }^{15}$ In addition, until foot off of the involved side, the trunk remains shifted toward the involved side, increasing the external adducting moments on the sound side and resulting in a greater power absorption in the hip than in the controls. This mechanism was previously seen in subjects with TTA when walking on level ground as well as when ascending stairs and was associated with a "hip-hike" strategy used to ensure the toe clearance. ${ }^{32,35}$ 


\section{Limitations}

Two main limiting factors affecting this study should be mentioned. First, using the standard gait model (Plug-in Gait), the foot is considered as a single rigid segment. The ankle kinematics and kinetics results may therefore be misleading; nevertheless, the ankle ROM acquired using this model should adequately represent the forefoot deformation of the prosthesis. Second, the sample size of the subjects with CA involved in this study was rather small, limiting the generalizability of these results. However, this is the first and apparently largest cohort study of which we are aware in which stair ascent was investigated for this condition using instrumented 3D gait analysis.

\section{Conclusion}

Subjects in whom a CA has been performed and who were provided with a clamshell device thereafter appear to experience functional problems due to limited dorsiflexion and missing active plantarflexion during stair ascent. This leads to an increased hip-flexing moment and reduced knee-flexing moment during WA on the involved side. Knee and hip moments on the sound side are increased to compensate for the impairment. The finding of the lateral trunk lean toward the involved side resembles findings in subjects with TTA for reasons which could not be fully clarified with this work.

\section{Acknowledgements}

The authors gratefully acknowledge the time and effort of all participants.

\section{Author contribution}

All authors contributed equally in the preparation of this manuscript.

\section{Clinical Trial}

"Biomechanical influence of the remaining range of Motion in the ankle Joint during walking," https://www.drks.de/drks_web/ navigate.do? navigation Id=trial. HTML\& T R IA L ID=DRKS00016771, DRKS00016771

\section{Data}

Please contact the corresponding author for data.

\section{Declaration of conflicting interests}

The author(s) declared no potential conflicts of interest with respect to the research, authorship, and/or publication of this article.

\section{Funding}

The author(s) disclosed receipt of the following financial support for the research, authorship, and/or publication of this article: This work was supported by the State of Baden-Württemberg
Medical Research Fund, Germany, via the Heidelberg University Hospital with grant number F.207233.

\section{ORCID iDs}

DWW Heitzmann iD https://orcid.org/0000-0001-8121-1923

SI Wolf (iD https://orcid.org/0000-0003-3921-6629

\section{References}

1. StatistischesBundesamt.Gesundheit.Fallpauschalenbezogene Krankenhausstatstik (DRG-Statistik) Diagnosen, Prozeduren, Fallpauschalen und Case Mix der vollstationären Patientinnen und Patienten in Krankenhäusern [Case-based hospital statics (DRG statistics) Diagnoses, procedures, case flat rates and case mix of full-time inpatients in hospitals]. Destatis 2017; 12: $1-7$.

2. Rammelt S, Olbrich A and Zwipp H. Amputationen am Rückfuß [Amputations on the hindfoot]. Oper Orthopade Traum 2011; 23: 265-279.

3. Bowker JH. Partial foot amputations and disarticulations: surgical aspects. J Prosthet Orthot 2007; 19: 62-76.

4. Krause FG, Pfander G, Henning J, et al. Ankle dorsiflexion arthrodesis to salvage Chopart's amputation with anterior skin insufficiency. Foot Ankle Int 2013; 34(11): 1560-1568.

5. Dillon MP, Fatone S and Hodge MC. Biomechanics of ambulation after partial foot amputation: a systematic literature review. J Prosthet Orthot 2007; 19: 2-35.

6. Greitemann B, Brückner L, Schäfer M, et al. Amputation und Prothesenversorgung: Indikationsstellung-operative Technik-Nachbehandlung-Funktionstraining [Amputation and prosthesis treatment: indication-operative technique post-treatment function training]. New York: Georg Thieme Verlag Stuttgart, 2016.

7. Burger H, Erzar D, Maver T, et al. Biomechanics of walking with silicone prosthesis after midtarsal (Chopart) disarticulation. Clin Biomech (Bristol, Avon) 2009; 24(6): 510-516.

8. Dillon MP and Barker TM. Comparison of gait of persons with partial foot amputation wearing prosthesis to matched control group: observational study. J Rehabil Res Dev 2008; 45(9): 1317-1334.

9. Dillon MP and Barker TM. Can partial foot prostheses effectively restore foot length. Prosthet Orthot Int 2006; 30(1): 17-23.

10. Nadeau S, McFadyen BJ and Malouin F. Frontal and sagittal plane analyses of the stair climbing task in healthy adults aged over 40 years: what are the challenges compared to level walking? Clin Biomech (Bristol, Avon) 2003; 18(10): 950-959.

11. Protopapadaki A, Drechsler WI, Cramp MC, et al. Hip, knee, ankle kinematics and kinetics during stair ascent and descent in healthy young individuals. Clin Biomech (Bristol, Avon) 2007; 22(2): 203-210.

12. McFadyen BJ and Winter DA. An integrated biomechanical analysis of normal stair ascent and descent. J Biomech 1988; 21(9): 733-744.

13. Reid SM, Lynn SK, Musselman RP, et al. Knee biomechanics of alternate stair ambulation patterns. Med Sci Sports Exerc 2007; 39(11): 2005-2011.

14. Vack HJ, Nielsen DH and Shurp DG. Kinetic patterns during stair ascent in patients with transtibial amputations 
using three different prostheses. J Prosthet Orthot 1999; 11 : $57-62$.

15. Schmalz T, Blumentritt S and Marx B. Biomechanical analysis of stair ambulation in lower limb amputees. Gait Posture 2007; 25(2): 267-278.

16. Aldridge Whitehead JM, Russell Esposito E and Wilken JM. Stair ascent and descent biomechanical adaptations while using a custom ankle-foot orthosis. J Biomech 2016; 49(13): 2899-2908.

17. Gailey RS, Roach KE, Applegate EB, et al. The Amputee Mobility Predictor: an instrument to assess determinants of the lower-limb amputee's ability to ambulate. Arch Phys Med Rehabil 2002; 83(5): 613-627.

18. Harrington ED, Lin RS and Gage J. Use of the anterior floor reaction orthosis in patients with cerebral palsy. Orthot Prosthet 1984; 37: 34-42.

19. Lucareli PR, Lima Mde O, Lucarelli JG, et al. Changes in joint kinematics in children with cerebral palsy while walking with and without a floor reaction ankle-foot orthosis. Clinics (Sao Paulo) 2007; 62(1): 63-68.

20. Rogozinski BM, Davids JR, Davis RB III, et al. The efficacy of the floor-reaction ankle-foot orthosis in children with cerebral palsy. J Bone Joint Surg Am 2009; 91(10): 2440-2447.

21. Blumentritt S, Schmalz T and Jarasch R. Significance of static prosthesis alignment for standing and walking of patients with lower limb amputation. Orthopade 2001; 30(3): 161-168.

22. Nietert M. Das Kniegelenk des Menschen als biomechanisches Problem [The human knee-joint as a biomechanical problem]. Biomed Tech 1977; 22: 13-21.

23. Putz C, Alimusaj M, Heitzmann DWW, et al. ExoProthesenregister. Trauma Berufskrankheit 2018; 20: 145150.

24. Hoffman M, Schrader J, Applegate T, et al. Unilateral postural control of the functionally dominant and nondominant extremities of healthy subjects. J Athl Train 1998; 33(4): 319-322.
25. Davis R, Ounpuu S, Tyburski D, et al. A gait analysis data collection and reduction technique. Hum Movement Sci 1991; 10: 575-587.

26. Kadaba MP, Ramakrishnan HK and Wootten ME. Measurement of lower extremity kinematics during level walking. J Orthop Res 1990; 8(3): 383-392.

27. Krautwurst BK, Wolf SI, Heitzmann DW, et al. The influence of hip abductor weakness on frontal plane motion of the trunk and pelvis in patients with cerebral palsy. Res Dev Disabil 2013; 34(4): 1198-1203.

28. Simon JR, Alimusaj M and Wolf SI. Kinetics on ramps and stairs using floor level mounted force plates. Gait Posture 2007; 26: S11-S12.

29. Novak AC. Biomechanical and physical requirements of stair negotiation with respect to aging and stroke. Doctoral Dissertation, Queen's University, Kingston, ON, Canada, 2011.

30. Alimusaj M, Fradet L, Braatz F, et al. Kinematics and kinetics with an adaptive ankle foot system during stair ambulation of transtibial amputees. Gait Posture 2009; 30(3): 356-363.

31. Molina Rueda F, Alguacil Diego IM, Molero Sanchez A, et al. Knee and hip internal moments and upper-body kinematics in the frontal plane in unilateral transtibial amputees. Gait Posture 2013; 37(3): 436-439.

32. Murray AM, Gaffney BM, Davidson BS, et al. Biomechanical compensations of the trunk and lower extremities during stepping tasks after unilateral transtibial amputation. Clin Biomech (Bristol, Avon) 2017; 49: 64-71.

33. Hendershot BD and Wolf EJ. Three-dimensional joint reaction forces and moments at the low back during over-ground walking in persons with unilateral lower-extremity amputation. Clin Biomech (Bristol, Avon) 2014; 29(3): 235-242.

34. Dillon MP, Fatone S and Hansen AH. Effect of prosthetic design on center of pressure excursion in partial foot prostheses. J Rehabil Res Dev 2011; 48(2): 161-178.

35. Michaud SB, Gard SA and Childress DS. A preliminary investigation of pelvic obliquity patterns during gait in persons with transtibial and transfemoral amputation. J Rehabil Res Dev 2000; 37(1): 1-10. 